Revta brasil. Bot., São Paulo,V.24, n.4 (suplemento), p.587-594, dez. 2001

\title{
Crescimento in vitro de linhagens de coloração vermelha e verde clara de Gracilaria birdiae (Gracilariales, Rhodophyta) em dois meios de cultura: análise de diferentes estádios reprodutivos
}

\author{
SUZANA URSI ${ }^{1}$ e ESTELA MARIA PLASTINO ${ }^{1,2}$
}

(recebido: 6 de setembro de 2000; aceito: 19 de julho de 2001)

\begin{abstract}
Growth of reddish and light green strains of Gracilaria sp. (Gracilariales, Rhodophyta) in two culture media: analysis of different reproductive phases). Gracilaria sp. is one of the main species collected for agar production in Brazil nowadays. The aim of this work was to compare the in vitro growth of different reproductive phases of wild specimens (reddish) and a color strain (light green) of Gracilaria sp., when cultivated in two culture media: Von Stosch and Provasoli. Six strains were selected: reddish (rd) and light green $(\mathrm{lg})$ gametophytes, both female $(\mathrm{F})$ and male $(\mathrm{M})$; reddish tetrasporophytes, but obtained from different crosses, Frd x Mrd and Flg x Mrd. The growth rates, which were analysed for 28 days, were calculated using fresh mass (mGR) and length (GR). The light green strain showed lower mGR and lGR than the reddish specimens. The growth was satisfatory in both culture media for wild strains. Reddish and light green male gametophytes and reddish tetrasporophytes showed higher mGR and lGR when cultivated in Provasoli. Light green female gametophytes showed similar mGR in both culture media, but the lGR were higher in Von Stosch. The IGR of tetrasporophytes derived from crosses Frd x Mrd were higher than the tetrasporophytes derived from Flg x Mrd.

RESUMO - (Crescimento in vitro de linhagens de coloração vermelha e verde clara de Gracilaria sp. (Gracilariales, Rhodophyta) em dois meios de cultura: análise de diferentes estádios reprodutivos). Gracilaria sp. é uma das principais macroalgas marinhas atualmente coletadas para produção de ágar no Brasil. Este trabalho objetivou comparar o crescimento in vitro de diferentes estádios reprodutivos tanto de linhagens selvagens (vermelhas), quanto de uma variante cromática (verde clara) de Gracilaria sp., em dois meios de cultura: Von Stosch e Provasoli. Seis linhagens foram selecionadas: gametófitos femininos (F) e masculinos (M), vermelhos (vm) e verde claros (vc); tetrasporófitos vermelhos, porém derivados de cruzamentos distintos, Fvm x Mvm e Fve x Mvm. As taxas de crescimento avaliadas por 28 dias, foram calculadas a partir de medidas de massa fresca $(\mathrm{TCm})$ e comprimento $(\mathrm{TCc})$. A variante cromática apresentou TCm e TCc inferiores às verificadas para espécimes selvagens. Os dois tipos de meio de cultura resultaram em crescimento satisfatório para as linhagens selvagens. Gametófitos masculinos vermelhos e verde claros e tetrasporófitos vermelhos apresentaram TCm e TCc superiores quando cultivados em Provasoli. Gametófitos femininos verde claros apresentaram TCm semelhantes nos dois meios de cultura, mas as TCs foram superiores em Von Stosch. As TCs de tetrasporófitos derivados de cruzamentos Fvm x Mvm foram superiores às verificadas para tetrasporófitos derivados de cruzamentos Fve x Mvm.
\end{abstract}

Key words - Gracilaria, growth, color strain, reproductive stage, culture medium

\section{Introdução}

O gênero Gracilaria tem sido alvo da atenção de inúmeros pesquisadores devido, principalmente, a seu conteúdo em agar (Oliveira \& Plastino 1994, Kain \& Destombe 1995). A maioria dos atuais avanços biotecnológicos não teria sido possível sem a utilização deste ficocolóide (Carté 1996), que é empregado em géis para eletroforese, como

1. Universidade de São Paulo, Instituto de Biociências, Departamento de Botânica, caixa postal 11461, 05422-970, São Paulo, SP, Brasil

2. Autor para correspondência: emplasti@.ubirdiaebr componente de meios de cultura sólidos (Radmer 1996), bem como em alimentos industriais (Glickman 1987, Matulewicz 1996). O interesse na implantação de cultivos comerciais de Gracilaria é crescente. No Brasil, apesar do consumo de ficocolóides encontrar-se em franca expansão (Furtado 1999), as tentativas de cultivos comerciais foram mal sucedidas (Oliveira \& Miranda 1998). A falta de conhecimento mais detalhado da biologia das espécies passíveis de cultivo vem sendo apontada como uma das razões do insucesso destes cultivos (Oliveira 1981, 1998). Este conhecimento também é fundamental para o manejo e o desenvolvimento das estratégias de coleta de bancos naturais (Alveal 1996, Critchley 1997). 
Estudos em laboratório têm contribuído para a implantação de cultivos comerciais em diversos países (Armisen 1995), uma vez que a utilização de condições controladas permite comparar o comportamento de espécies ou linhagens distintas, fornecendo dados valiosos para uma análise preliminar da viabilidade de um cultivo comercial em determinada região (Oliveira et al. 1995). Embora experimentos in vitro em condições não axênicas sejam reconhecidamente valiosos, é fundamental que aspectos básicos também sejam contemplados. Dentre estes, destaca-se o tipo de meio de cultura a ser utilizado. O emprego inadequado de um tipo de meio pode comprometer a interpretação dos resultados obtidos. Portanto, investigações visando estabelecer as melhores condições para o cultivo in vitro de uma determinada espécie são fundamentais, conferindo maior confiabilidade aos resultados obtidos em experimentos laboratoriais.

O cultivo in vitro não axênico tem sido uma importante técnica utilizada em investigações sobre diversidade intraespecífica, especialmente as relacionadas à caracterização de variantes cromáticas. Estas variantes são referidas para vários gêneros de Rhodophyta, dentre estes Gracilaria (van der Meer 1990). Tais variantes vêm sendo utilizadas como ferramentas em estudos sobre diversos processos biológicos, como fotossíntese, diferenciação morfológica e sexualidade. Linhagens mais adequadas a maricultura também vêm sendo selecionadas (van der Meer 1986).

Gracilaria sp.Plastino \& Oliveira referida como Gracilaria sp. 3 por Plastino (1991), é uma das principais espécies atualmente coletadas e processadas para produção de ágar no país. A descoberta de uma variante de coloração verde clara em uma população natural (E.M. Plastino, S. Ursi \& M.T. Fujii, dados não publicados) vem permitindo novas abordagens referentes à sua diversidade intraespecifica. Diferentes linhagens procedentes desta população já foram isoladas em laboratório, como gametófitos femininos e masculinos, tanto de coloração vermelha (selvagem) quanto de coloração verde clara, e tetrasporófitos de coloração vermelha.

O objetivo do presente trabalho foi realizar uma análise comparativa das taxas de crescimento in vitro de diferentes estádios reprodutivos de
Gracilaria sp., tanto de espécimes selvagens quanto da variante cromática. Visou ainda determinar qual, dentre dois meios de cultura, é o mais adequado para o cultivo destas linhagens: Von Stosch ou Provasoli.

\section{Material e métodos}

Material biológico - Gracilaria sp. é uma espécie ainda não formalmente descrita (E.M. Plastino \& E.C. Oliveira, dados não publicados). São plantas cilíndricas, de coloração vermelho-vinácea, de até $46 \mathrm{~cm}$ de comprimento, apresentando um apressório de onde partem um ou mais ramos cilíndricos com ramificações pseudodicotômicas irregulares, freqüentemente unilaterais e de segunda ordem. $\mathrm{O}$ talo tem organização microcistideada com células pequenas na medula. Os espermatângios estão reunidos em conceptáculos na forma de criptas fundidas do tipo henriquesiana (sensu Yamamoto 1984). Os cistocarpos possuem uma constrição basal nítida, ostíolo proeminente e carposporófito com ampla região de contato com o gametófito. A célula de fusão é extremamente ramificada.

O material biológico utilizado nos experimentos foi obtido a partir do cultivo unialgal de tetrásporos liberados por um tetrasporófito de coloração vermelha de Gracilaria sp., coletado na praia de Parati, município de Anchieta (20 $20^{\circ} \mathrm{S}$ e $40^{\circ} 65^{\prime}$ W), Espírito Santo por M.T. Fujii em 22/08/1994. As culturas unialgais de Gracilaria birdiae foram estabelecidas utilizando-se os procedimentos descritos em Plastino \& Oliveira (1990). Seis linhagens foram selecionadas: gametófitos femininos (F) e masculinos (M), vermelhos (vm) e verde claros (vc); e tetrasporófitos vermelhos, porém derivados de cruzamentos distintos, Fvm x Mvm e Fvc x Mvm. Os espécimes utilizados nos experimentos não apresentavam estruturas reprodutivas.

Desenho experimental - As condições gerais de cultivo foram: água do mar com salinidade de $32 \%$ e pH de 7,9, temperatura de $24-26^{\circ} \mathrm{C}$; fotoperíodo de 14 horas de luz e 10 de escuro; irradiância de $120 \mu \mathrm{mol}$ fótons. $\mathrm{m}^{-2} \cdot \mathrm{s}^{-1}$; e aeração em intervalos de 30 minutos. Estas mesmas condições foram empregadas nos experimentos descritos a seguir.

Três repetições por linhagem foram cultivadas em dois meios de cultura distintos a 50\%: Von Stosch e Provasoli (tabela 1). Cada repetição era composta de três ápices de 1 $\mathrm{cm}$, derivados de espécimes distintos e cultivados em $800 \mathrm{ml}$ de água do mar enriquecida com meio de cultura. $\mathrm{O}$ crescimento foi avaliado durante um mês por medidas de massa fresca e comprimento. Estas medidas foram utilizadas para o cálculo das taxas de crescimento segundo a fórmula: $\mathrm{TC}=[(\mathrm{Mf} / \mathrm{Mi})$ 1/t -1$]$ x 100\% (Lignell \& Pedersén 1989); onde TC, taxa de crescimento; Mf, medida final; Mi, medida inicial; e t, tempo.

Duas análises de variância bifatoriais foram realizadas para cada estádio reprodutivo, uma referente às taxas de crescimento calculadas a partir das medidas de massa fresca, e outra referente às taxas calculadas a partir das medidas de comprimento. As variáveis utilizadas para os gametófitos foram a coloração do talo e o meio de cultura. Quanto aos 
Tabela 1. Concentrações $\left(\mathrm{L}^{-1}\right)$ dos compostos dos meios de cultura Von Stosch (Edwards (1970), com modificações segundo Plastino (1985) e Provasoli (McLachlan 1973).

\begin{tabular}{lcc}
\hline Compostos & Von Stosch & Provasoli \\
\hline $\mathrm{NaNO}_{3}$ & $0,50 \mathrm{mM}$ & $0,66 \mathrm{mM}$ \\
$\mathrm{Na}_{2}$-glicerafosfato. $5 \mathrm{H}_{2} \mathrm{O}$ & - & $25,00 \mu \mathrm{M}$ \\
$\mathrm{Na}_{2} \mathrm{HPO}_{4} \cdot 12 \mathrm{H}_{2} \mathrm{O}$ & $30,00 \mu \mathrm{M}$ & - \\
$\mathrm{MnSO}_{4} \cdot \mathrm{H}_{2} \mathrm{O}$ & $0,10 \mu \mathrm{M}$ & $7,30 \mu \mathrm{M}$ \\
$\mathrm{FeCl}_{3} \cdot 6 \mathrm{H}_{2} \mathrm{O}$ & $01,15 \mu \mathrm{M}$ & $1,80 \mu \mathrm{M}$ \\
$\mathrm{Fe}_{\mathrm{EDTA}}$ & - & $7,20 \mu \mathrm{M}$ \\
$\mathrm{H}_{3} \mathrm{BO}_{3}$ & - & $185,00 \mu \mathrm{M}$ \\
$\mathrm{ZnSO}_{4} \cdot 7 \mathrm{H}_{2} \mathrm{O}$ & - & $0,80 \mu \mathrm{M}$ \\
$\mathrm{CoSO}_{4} \cdot 7 \mathrm{H}_{2} \mathrm{O}$ & - & $0,17 \mu \mathrm{M}$ \\
Tiamina & $0,59 \mu \mathrm{M}$ & $0,06 \mu \mathrm{M}$ \\
Biotina & $4,10 \mathrm{nM}$ & $3,57 \mathrm{nM}$ \\
Cianoc obalamina & $0,74 \mathrm{nM}$ & $1,18 \mathrm{nM}$ \\
Tampão TRIS (I) & - & $0,66 \mathrm{mM}$ \\
EDTA (II) & $12,70 \mu \mathrm{M}$ & $26,90 \mu \mathrm{M}$ \\
\hline
\end{tabular}

(I). Tris(hidroximetil)aminometano. O pH foi ajustado para 7,8 utilizando-se $\mathrm{HCl} 5 \mathrm{~N}$. (II) Etilenodiaminotetracetato de sódio.

tetrasporófitos, utilizou-se como variáveis o tipo de cruzamento e o meio de cultura.

Duas análises de variância bifatoriais também foram utilizadas na comparação de espécimes de mesma coloração de talo, porém de diferentes estádios reprodutivos, uma referente às taxas de crescimento calculadas a partir das medidas de massa fresca e outra referente às taxas calculadas a partir das medidas de comprimento. Tanto para espécimes de coloração vermelha, quando de coloração verde clara, as variáveis utilizadas foram o estádio reprodutivo e o meio de cultura.

Quando necessário, o teste a posteriori Newman-Keuls foi realizado após as análises de variância (Zar 1999). Os cálculos estatísticos foram feitos com o auxílio do módulo ANOVA/MANOVA do programa Statistica (versão 5.0).

\section{Resultados}

Espécimes de coloração vermelha de Gracilaria sp. apresentaram taxas de crescimento calculadas a partir de medidas de massa fresca $(\mathrm{TCm})$ superiores às obtidas para espécimes de coloração verde clara, independentemente do estádio reprodutivo ou do meio de cultura (gametófitos femininos. $\mathrm{F}=320,162, \mathrm{P}<0,001$; gametófitos masculinos. $\mathrm{F}=111,794, \mathrm{P}<0,001)$ (figura 1). Resultados semelhantes foram observados para as taxas de crescimento calculadas a partir de medidas de comprimento (TCc) (gametófitos femininos. $\mathrm{F}=363,528, \mathrm{P}<0,001$; gametófitos masculinos. $\mathrm{F}=125,183, \mathrm{P}<0,001$ ) (figura 2). Estes resultados são ilustrados pelo aspecto geral dos ápices após 28 dias de cultivo (figura 3).

Tetrasporófitos derivados dos cruzamentos Fvm x Mvm e Fvc x Mvm apresentaram TCm semelhantes, quando cultivados em um mesmo tipo de meio de cultura $(\mathrm{F}=5,249, \mathrm{P}=0,051)$. No entanto, as TCc de tetrasporófitos derivados do cruzamento Fvm x Mvm foram superiores às verificadas para tetrasporófitos derivados do cruzamento Fvc x Mvm, independentemente do meio de cultura empregado nos cultivos $(\mathrm{F}=15,069$, $\mathrm{P}=0,005$ ) (figuras 1,2$)$. A figura 3 ilustra esta diferença de comprimento verificada entre tetrasporófitos.

Gametófitos femininos apresentaram TCm semelhantes quando cultivados em Provasoli e Von Stosch $(\mathrm{F}=0,008, \mathrm{P}=0,930)$ (figura 1$)$. Quanto às TCc, verificou-se efeito significativo do meio de cultura $(F=15,466, P=0,004)$. No entanto, o teste a posteriori demonstrou que este efeito foi válido apenas para espécimes de coloração verde clara, 
que apresentaram TCc superiores em Von Stosch, quando comparadas às verificadas em Provasoli. Já as TCc de espécimes de coloração vermelha foram semelhantes nos dois meios de cultura (figura 2).

As TCm e TCc de gametófitos masculinos cultivados em meio Provasoli foram superiores às verificadas em Von Stosch (TCm F = 37,367, P < 0,001 ; TCc. $\mathrm{F}=80,232, \mathrm{P}<0,001$ ) (figuras 1,2 ). Tetrasporófitos cultivados em Provasoli também apresentaram TCm e TCc superiores às verificadas para espécimes cultivados Von Stosch (TCm. F = $18,484, \mathrm{P}=0,003$; TCc. $\mathrm{F}=40,146, \mathrm{P}<0,001$ ) (figuras 1, 2).

Diferenças foram verificadas entre as $\mathrm{TCm}$ e TCc de espécimes selvagens de diferentes estádios reprodutivos $(\mathrm{TCm} . \mathrm{F}=6,153, \mathrm{P}<0,01$; TCc. $\mathrm{F}=$ $100,717, \mathrm{P}<0,001)$. Quando cultivados em meio Von Stosch, gametófitos femininos apresentaram $\mathrm{TCm}$ e $\mathrm{TCc}$ superiores às verificadas para gametófitos masculinos e tetrasporófitos. Já em meio Provasoli, as TCm e TCc foram semelhantes para estes três estádios reprodutivos (figuras 1,2).

Quanto às linhagens variantes, gametófitos femininos e masculinos apresentaram TCm semelhantes, independentemente do meio utilizado nos cultivos $(\mathrm{F}=1,629, \mathrm{P}=0,238)$ (figura 1$)$. As TCc de gametófitos femininos e masculinos cultivados em meio Provasoli também foram semelhantes. No entanto, as TCc de gametófitos femininos cultivados em meio Von Stosch foram superiores às verificadas para gametófitos masculinos $(\mathrm{F}=42,536, \mathrm{P}<0,001)$ (figura 2$)$.

\section{Discussão}

O desenvolvimento somático da variante verde clara de Gracilaria birdiae foi deficiente, quando comparado ao de espécimes de coloração vermelha, independentemente do estádio reprodutivo analisado ou do tipo de meio de cultura empregado nos cultivos. Estes resultados são semelhantes aos verificados para a maioria das variantes cromáticas de Rhodophyta, que apresentou um menor desempenho, quando comparadas aos tipos selvagens (van der Meer 1990). No entanto, em alguns casos, este desempenho foi semelhante ou até superior (Ramus \& van der Meer 1983, Dawes et al. 1994,
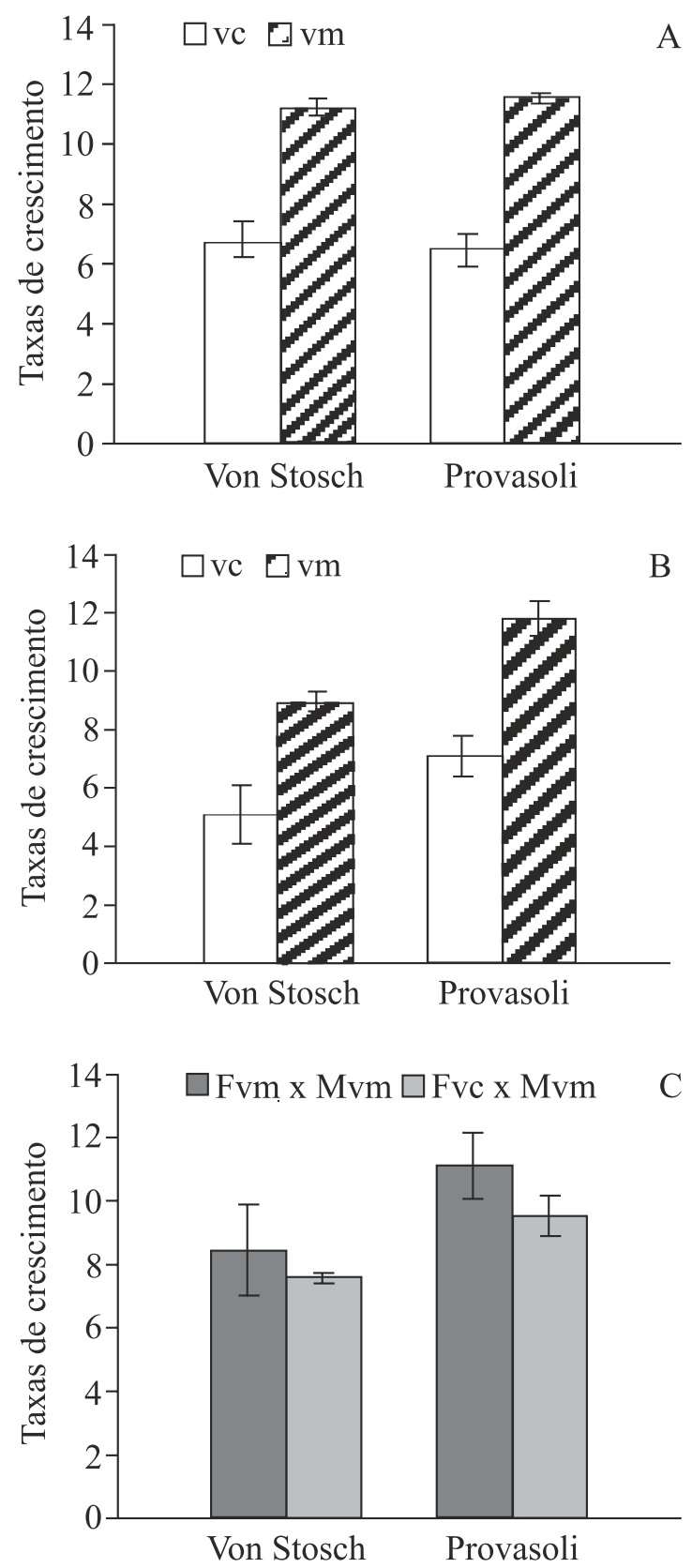

Figura 1. Taxas de crescimento ( $\mathrm{Dia}^{-1}$, média \pm desvio padrão) calculadas a partir das medidas de massa fresca de espécimes de coloração vermelha (vm) e verde clara (vc) de Gracilaria sp. cultivados durante 28 dias em meio de cultura Von Stosch e Provasoli. A. gametófitos femininos; B. gametófitos masculinos; $\mathrm{C}$. tetrasporófitos ( $\mathrm{F}=$ gametófitos femininos; $\mathrm{M}=$ gametófitos masculinos). Fórmula utilizada para o cálculo das taxas de crescimento, $\mathrm{TC}=\left[(\mathrm{Mf} / \mathrm{Mi})^{1 / \mathrm{t}}-1\right] \times 100 \%$ (Lignell \& Pedersén 1989); onde TC, taxa de crescimento; Mf, medida final; Mi, medida inicial; e t, tempo. 
Guimarães 2000). Variantes verdes de gêneros de grande importância econômica, como Eucheuma e Kappaphycus, vêm sendo amplamente selecionadas e utilizadas em cultivos comerciais (Dawes 1992, 1995, Paula et al. 1999). Porém, apenas uma variante de coloração verde de Gracilaria tem sido comercializada em pequena escala para consumo humano (Patwary \& van der Meer 1992).

A observação de baixas taxas de crescimento para a variante verde clara de Gracilaria sp. é compatível com o fato desta variante ser tão raramente encontrada na natureza. Nas duas vezes em que espécimes desta coloração foram coletados, tratavam-se de gametófitos crescendo como epífitas de tetrasporófitos selvagens. Estas baixas taxas de crescimento podem estar relacionadas a uma deficiência fotossintética da variante verde clara, já que esta possui concentrações de pigmentos bastante inferiores às verificadas para linhagens selvagens (E.M. Plastino, S. Ursi \& M.T. Fujii, dados não publicados). Devido às características apresentadas, esta variante pode se tornar uma importante ferramenta para futuras investigações sobre processos fisiológicos, principalmente aqueles relacionados ao aparelho fotossintético.

Embora tetrasporófitos e gametófitos femininos e masculinos de Gracilaria sejam geralmente isomórficos, diferenças fisiológicas entre estes estádios já foram referidas (Kain \& Destombe 1995). Tais diferenças, avaliadas por meio das taxas de crescimento, foram reportadas para espécies como G. bursapastoris (Gmelin) Silva, G. coronopifolia Agarth (Hoyle 1978), G. tikvahiae McLachlan (Patwary \& van der Meer 1983), G. sjoestedtii Kylin (Zhang \& van de Meer 1988) e G. chilensis Bird, McLachlan \& Oliveira (Santelices \& Varela 1995). Respostas fisiológicas distintas também foram verificadas entre os estádios reprodutivos de Gracilaria birdiae, quando cultivados em meio de cultura Von Stosch. Gametófitos femininos apresentaram maiores taxas de crescimento quando comparadas às verificadas para gametófitos masculinos e tetrasporófitos. No entanto, estes estádios reprodutivos apresentaram crescimento semelhante quando cultivados em Provasoli.
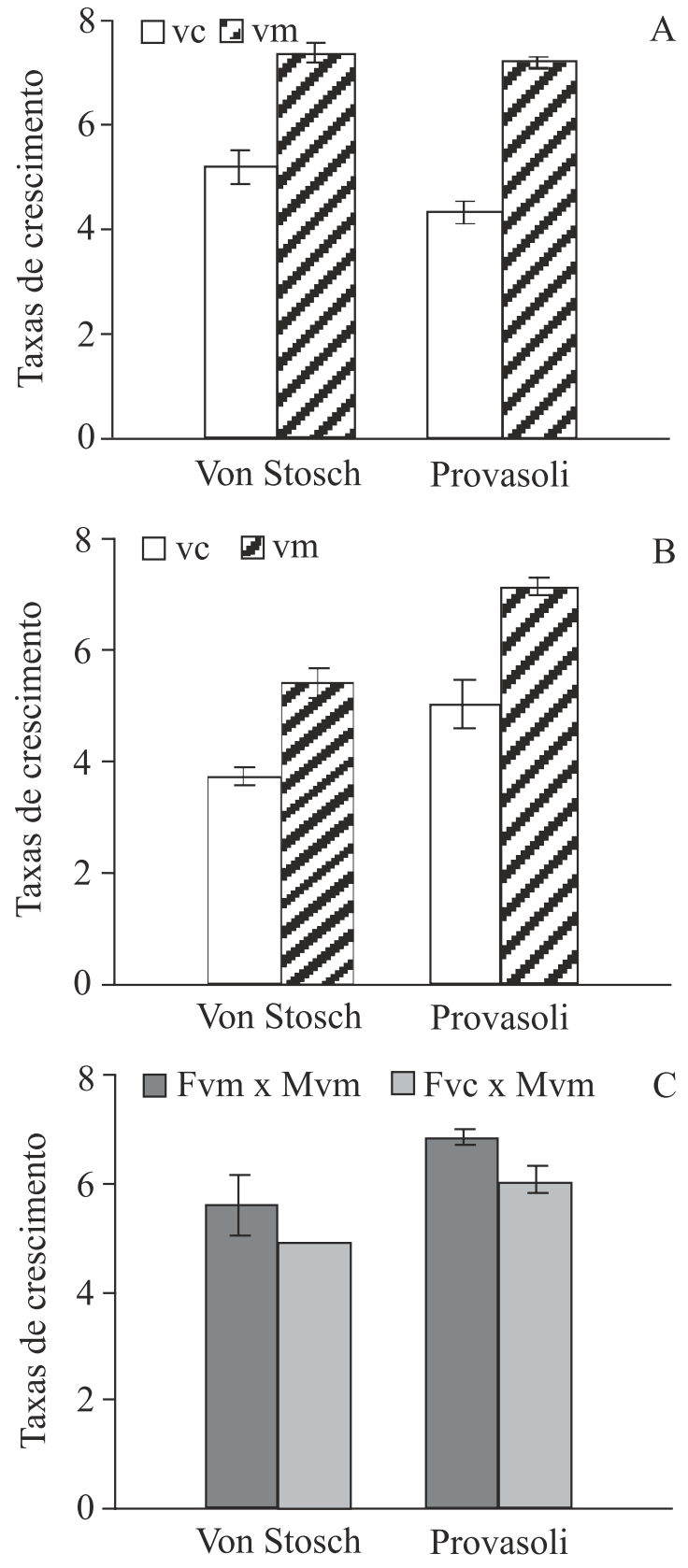

Figura 2. Taxas de crescimento ( $\mathrm{Dia}^{-1}$, média + desvio padrão) calculadas a partir das medidas de comprimento de espécimes de coloração vermelha (vm) e verde clara (vc) de Gracilaria sp. cultivados durante 28 dias em meio de cultura Von Stosch e Provasoli. A. gametófitos femininos; B. gametófitos masculinos; $\mathrm{C}$. tetrasporófitos $(\mathrm{F}=$ gametófitos femininos; $\mathrm{M}=$ gametófitos masculinos). Fórmula utilizada para o cálculo das taxas de crescimento, $\mathrm{TC}=\left[(\mathrm{Mf} / \mathrm{Mi})^{1 / \mathrm{t}}-1\right] \times 100 \%$ (Lignell \& Pedersén 1989); onde TC, taxa de crescimento; Mf, medida final; Mi, medida inicial; e t, tempo. 


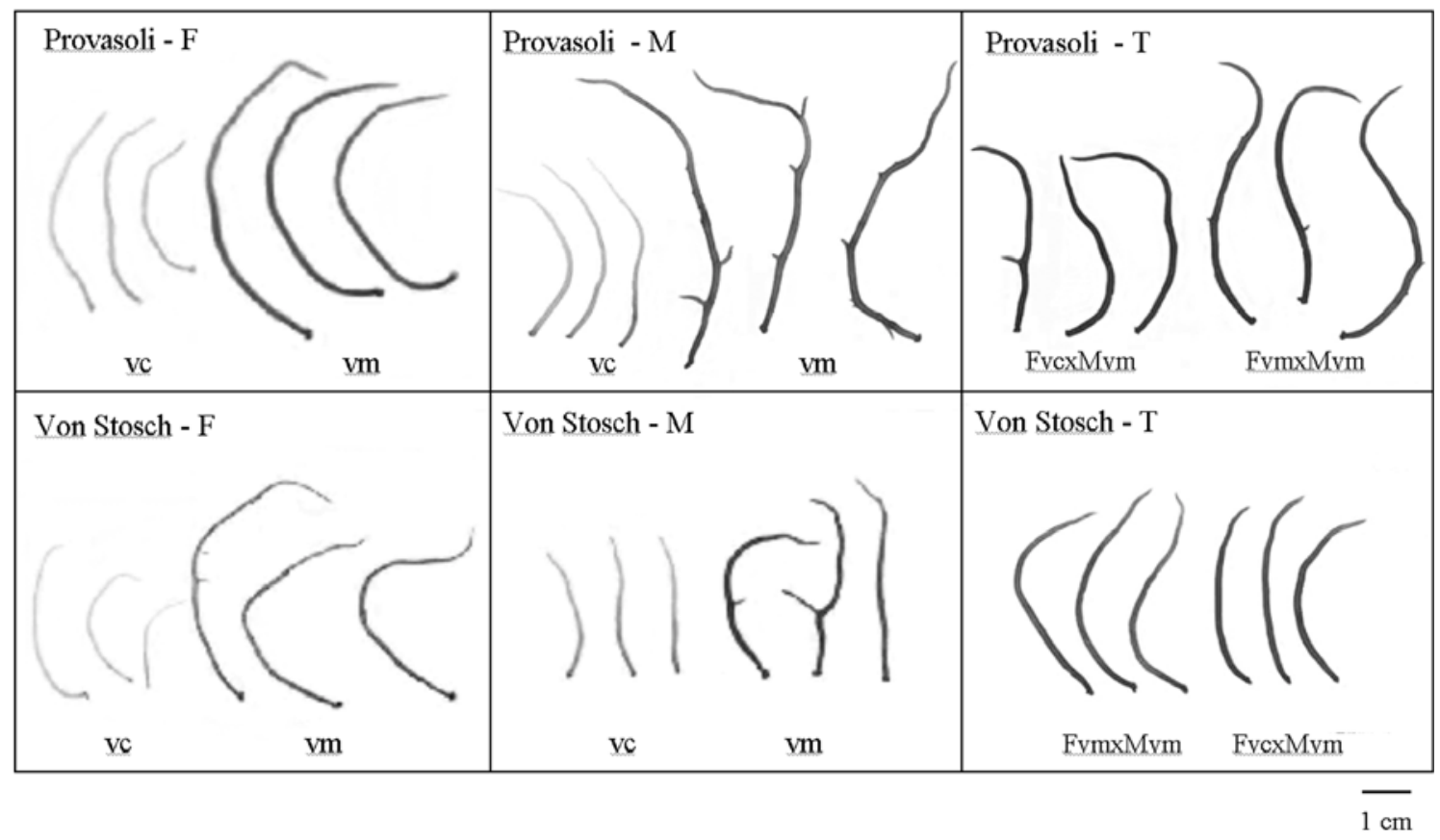

Figura 3. Aspecto geral de ramos de diferentes linhagens de Gracilaria birdiae após 28 dias de cultivo em meio Provasoli e Von Stosch. F, gametófitos femininos. M, gametófitos masculinos. T tetrasporófitos. vm, talo de coloração vermelha. vc, talo de coloração verde clara.

Gracilaria sp. apresentou crescimento satisfatório nos dois meios de cultura testados, uma vez que as diferenças obtidas entre as taxas de crescimento de ápices de uma mesma linhagem não foram muito acentuadas quando estes foram cultivados em meios distintos, independentemente da linhagem testada. O tipo de meio de cultura mais adequado para o cultivo in vitro de Gracilaria sp. variou de acordo com o estádio reprodutivo. Desta forma, não é possível estabelecer um meio como o mais adequado para o cultivo in vitro desta espécie sem levarmos em consideração sua diversidade intraespecífica. Gametófitos femininos apresentaram crescimento semelhante em meio Von Stosch e Provasoli. No entanto, o crescimento de gametófitos masculinos e tetrasporófitos foi superior em meio Provasoli, quando comparado ao de espécimes cultivados em Von Stosch. Tais resultados sugerem que os estádios reprodutivos de Gracilaria sp. apresentam necessidades nutricionais distintas, uma vez que os dois meios de cultura testados são bastante diferentes. Embora os dois meios tenham componentes em comum, estes se apresentam em diferentes proporções. O composto utilizado como fonte de fósforo é inorgânico no meio Von Stosch $\left(\mathrm{Na}_{2} \mathrm{HPO}_{4} \cdot 12 \mathrm{H}_{2} \mathrm{O}\right)$, enquanto no Provasoli é orgânico $\left(\mathrm{Na}_{2}\right.$-glicerafosfato. $\left.5 \mathrm{H}_{2} \mathrm{O}\right)$, o que possibilita sua utilização também como fonte de carbono. Além disso, o meio Provasoli apresenta outros componentes que não fazem parte do meio Von Stosch, como: $\mathrm{H}_{3} \mathrm{BO}_{3}, \mathrm{ZnSO}_{4} .7 \mathrm{H}_{2} \mathrm{O}$, $\mathrm{CoSO}_{4} \cdot 7 \mathrm{H}_{2} \mathrm{O}, \mathrm{Fe}\left(\mathrm{NH}_{4}\right)_{2} \cdot 6 \mathrm{H}_{2} \mathrm{O}$ e o tampão Tris (hidroximetil) aminometano, cujo efeito tóxico já foi referido para algumas espécies de macroalgas marinhas (McLachlan 1973).

Uma espécie cujos estádios reprodutivos tivessem necessidades nutricionais distintas apresentaria vantagens adaptativas em ambientes heterogêneos, onde houvessem, por exemplo, variações na disponibilidade de nutrientes (Stebbins \& Hill 1980). Diferenças ecológicas entre estádios reprodutivos já foram demonstradas para Gracilaria. gracilis (Stackhouse) Steentoft, como 
G. verrucosa (Hudson) Papenfuss (Destombe et al. 1992, 1993). As diferenças fisiológicas verificadas entre os estádios reprodutivos de Gracilaria sp. podem ser uma evidencia da existência de estratégias ecológicas distintas entre estes estádios. No entanto, apesar dos estudos in vitro serem aceitos como bons indicativos dos fenômenos observados na natureza, deve-se considerar que, no ambiente natural, outros fatores estariam atuando, e as diferenças observadas entre os estádios de Gracilaria sp. poderiam ser acentuadas ou minimizadas. Desta forma, o presente trabalho abre espaço para novas abordagens, como estudos que permitam confirmar na natureza, as diferenças observadas in vitro. $\mathrm{O}$ conhecimento do desempenho fisiológico de espécimes de diferentes estádios reprodutivos na natureza poderia propiciar a seleção de linhagens mais produtivas, bem como fornecer subsídios para discussões mais abrangentes, relacionadas às possíveis vantagens adaptativas da alternância de gerações isomórficas na espécie.

Também foi possível verificar diferenças fisiológicas entre linhagens selvagens de um mesmo estádio reprodutivo de Gracilaria sp. As diferenças verificadas entre as TCc de tetrasporófitos de coloração vermelha derivados dos cruzamentos Fvm x Mvm e Fvc x Mvm sugerem que, embora apresentem fenótipos semelhantes, o comportamento fisiológico de tais linhagens pode estar relacionado aos prováveis genótipos distintos que possuem. Estudos mais aprofundados, principalmente relacionados ao tipo de herança da cor do talo, são necessários para o melhor conhecimento dos processos responsáveis por esta diversidade.

Agradecimentos - À FAPESP pelo auxílio concedido (Proc. 98/11943-1); ao CNPq pelas bolsas de mestrado e pesquisa concedidas para a primeira e segunda autoras, respectivamente (Proc. 132846/98-5 e 300148/93-3).

\section{Referências bibliográficas}

ALVEAL, K. 1996. Manejo de algas marinas comerciales. In Macroalgas de interes económico. Cultivo, manejo, industrualización (M. Ferrario, \& E. Sar, eds.). Editorial de la Universidad Nacional de La Plata, La Plata, p.57-88.

ARMISEN, R. 1995. World-wide use and importance of Gracilaria. Journal of Applied Phycology 7:231-243.
CARTÉ, B.K. 1996. Biomedical potential of marine natural products. Biocience 46:271-286.

CRITCHLEY, A.T. 1997. Gracilaria (Rhodophyta, Gracilariales): an economically important agarophyte. In Seaweed cultivation and marine ranching (M. Ohno, \& A.T. Critchley, eds.). JICA, Yokosuka, p.89-112.

DAWES, C.J. 1992. Irradiance acclimation of the cultured Philippine seaweeds, Kappaphycus alvarezii and Eucheuma denticulatum. Botanica Marina 35:189-195.

DAWES, C.J. 1995. The effect of nutrient and photon fluence on the photosynthetic responses of red and green pigmented cultivars of Eucheuma denticulatum. Botanica Marina 38:323-327.

DAWES, C.J., LLUISMA, A.O. \& TRONO, G.C. 1994. Laboratory and field growth studies of commercial strains of Eucheuma denticulatum and Kappaphycus alvarezii in the Philippines. Journal of Applied Phycology 6:21-24.

DESTOMBE, C., GODIN, J., LEFEBVRE, C., DEHORTER, O. \& VERNET, P. 1992. Differences in dispersal abilities of haploid and diploid spore of Gracilaria verrucosa (Gracilariales, Rhodophyta). Botanica Marina 35:93-98.

DESTOMBE, C., GODIN, J., NOCHER, M., RICHERD, S. \& VALERO, M. 1993. Differences in response between haploid and diploid isomorphic phases of Gracilaria verrucosa (Rhodophyta: Gigartinales) exposed to artificial environmental conditions. Hydrobiologia 260/ 261:131-137.

EDWARDS, P. 1970. Illustre ated guide of seaweeds and sea grasses in vicinity of Porto Arkansas, Texas. Contributions in Marine Science 15:1-228.

FURTADO, M.R. 1999. Alta lucratividade atrai investimento - Hidrocolóides. Química e derivados. 377:20-29.

GLICKMAN, M. 1987. Utilization of seaweed hydrocolloids in the food industry. Hydrobiologia 151/ 152:31-47.

GUIMARÃES, M. 2000. Aspectos fisiológicos de Gracilaria domingensis (Gracilariales, Rhodophyta): subsídios para a compreensão da manutenção do polimorfismo pigmentar. Tese de doutorado, Universidade de São Paulo, São Paulo.

HOYLE, M.D. 1978. Reproductive phenology and growth rates in two species of Gracilaria from Hawai. Journal of Experimental Marine Ecology 33:273-283.

KAIN, J.M. \& DESTOMBE, C. 1995. A review of life history, reproduction and phenology of Gracilaria. Journal of Applied Phycology 7:269-281.

LIGNELL, A. \& PEDERSÉN, M. 1989. Agar composition as a function of morphology and growth rate. Studies on some morphological strains of Gracilaria secundata and Gracilaria verrucosa (Rhodophyta). Botanica Marina 32:219-227.

MCLACHLAN, J. 1973. Growth media-marine. In Handbook of phycological methods. Cultures methods and growth measurements (J.R.Stein, ed.). Cambridge University Press, Cambridge, p.25-51. 
MATULEWICZ, M.C. 1996. Polisacáridos de algas rojas: Agar. In Macroalgas de interes económico. Cultivo, manejo, industrualización (M. Ferrario \& E. Sar, eds.). Editorial de la Universidad Nacional de La Plata, La Plata, p.111-133.

OLIVEIRA, E.C. 1981. A exploração de algas marinhas no Brasil: situação atual e perspectivas futuras. Phycologia Latino-Americana. 1:5-17.

OLIVEIRA, E.C. 1998. The seaweed resources of Brazil. In Seaweed resources of the world (A.T. Critchley \& M. Ohno, eds.). JICA, Yokosuka, p.366-371.

OLIVEIRA, E.C. \& MIRANDA, G.E.C. 1998. Aspectos sociais e econômicos da exploração de algas marinhas no Brasil. In Anais do IV Congresso Latinoamericano de Ficologia, Volume II Reunião Ibero-americana, VII Reunião Brasileira de Ficologia (E.J. Paula, M. Cordeiro-Marino, D.P. Santos, E.M. Plastino, M.T. Fujii, \& N.S. Yokoya, eds). Sociedade Ficológica da América Latina e Caribe Sociedade Brasileira de Ficologia, São Paulo,v.z p.359-369.

OLIVEIRA, E.C. \& PLASTINO, E.M. 1994. Gracilariaceae. In Biology of economic seaweeds (I. Akatsuka, ed.). SPB Academic Publishing, The Hague, p. 185-226.

OLIVEIRA, E.C., PAULA, E.J., PETTI, R. \& PLASTINO, E.M. 1995. Metodologias para cultivo no axênico de macroalgas marinas in vitro. In Manual de metodos fiicológicos (K. Alveal, M.E. Ferrario, E.C. Oliveira \& E. Sar, eds.). Universidad de Concepción, Concepción, p.429-447.

PATWARY, M.U. \& VAN DER MEER, J.P. 1983. Improvement of Gracilaria tikvahiae (Rhodophyceae) by genetic modification of thallus morphology. Aquaculture 33:207-214.

PATWARY, M.U. \& VAN DER MEER, J.P. 1992. Genetic and breeding of cultivated seaweeds. The Korean Journal of Phycology 7:281-318.

PAULA, E.J., TOLEDO, R. \& OHNO, M. 1999. Strain selection in Kappaphycus alvarezii var. alvarezii (Solieriaceae, Rhodophyta) using tetraspore progeny. Journal of Applied Phycology 11:111-121.

PLASTINO, E.M. 1985. As espécies de Gracilaria (Rhodophyta, Gigartinales) da Praia Dura, Ubatuba, SP -
Aspectos biológicos e fenologia. Dissertação de mestrado, Universidade de São Paulo, São Paulo.

PLASTINO, E.M. 1991. Cultivo in vitro, estudos reprodutivos e biossistemática de algas gracilarióides (Rhodophyta, Gracilariales) de talo cilíndrico. Tese de doutorado, Universidade de São Paulo, São Paulo.

PLASTINO, E.M. \& OLIVEIRA, E.C. 1990. Crossing experiments as an aid to the taxonomic recognition of the agarophyte Gracilaria (Rhodophyta, Gigartinales). In Cultivation of seaweeds in Latin American (E.C. Oliveira \& N. Kautsky, eds.). Universidade de São Paulo, São Paulo, p.127-133.

RADMER, R.J. 1996. Algal diversity and commercial algal products. BioScience 46:263-270.

RAMUS, J. \& VAN DER MEER, J.P. 1983. A physiological test of the theory of complementary chromatic adaptation. I. Color mutants of a red seaweed. Journal of Phycology 19:86-91.

SANTELICES, B. \& VARELA, D. 1995. Regenerative capacity of Gracilaria fragments: Effects of size, reproductive state and position along the axis. Journal of Applied Phycology 7:501-506.

STEBBINS, G.L. \& HILL, G.J. 1980. Did the multicellular plants invade the land? The American Naturalist 115:342-353.

VAN DER MEER, J.P. 1986. Genetic contributions to research on seaweeds. Progress in Phycological Research 4:1-38.

VAN DER MEER, J.P. 1990. Genetics. In Biology of the red algae (K. Cole \& R. Sheath, eds.). Cambridge University Press, Cambridge, p.103-122.

ZAR, J.H. 1999. Biostatistical analysis. 4ed. Upper Saddle River, New Jersey.

ZHANG, X. \& VAN DER MEER, J.P. 1988. A genetic study on Gracilaria sjoestedtii. Canadian Journal of Botany 66:2022-2026.

YAMAMOTO, H. 1984. An evaluation of some vegetative features and some interesting problems in Japanese populations of Gracilaria. Hydrobiologia 116/117:51-54. 